\title{
Drug Mass Transfer Mechanism, Thermodynamics, and In Vitro Release Kinetics of Antioxidant-encapsulated Zeolite Microparticles as a Drug Carrier System
}

\author{
Z. Lyubenova Yaneva, ${ }^{\mathrm{a},{ }^{, *}}$ N. Valkanova Georgieva, \\ L. Lyubomirova Bekirska, ${ }^{a}$ and S. Lavrova ${ }^{b}$ \\ ${ }^{a}$ Chemistry Unit, Department of Pharmacology, Animal Physiology \\ and Physiological Chemistry, Faculty of Veterinary Medicine, Trakia \\ University, Students Campus, 6000 Stara Zagora, Bulgaria \\ ${ }^{b}$ Faculty of Chemical System Engineering, University of Chemical \\ Technology and Metallurgy, 8, Kliment Ohridski Blvd., Sofia, Bulgaria
}

doi: 10.15255/CABEQ.2018.1319

Original scientific paper

Received: March 1, 2018

Accepted: September 7, 2018

\begin{abstract}
The aim of the present study was to develop a new vitamin E-zeolite drug carrier system, and investigate the mass transfer mechanism of the antioxidant encapsulation and release on/from the mineral matrix by thermodynamic and kinetics sorption/desorption experiments and mathematical modelling of the experimental data. The surface, morphological and spectral characteristics of the vitamin and the zeolite were determined by Boehm titration, SEM, FTIR and UV/Vis spectrophotometric analyses. Intraparticle diffusion was not the only rate-limiting mechanism, as the mixed-order kinetics model gave the highest regression coefficient $\left(R^{2}\right)$ and lowest SSE, MSE, RMSE, and $\mathrm{AIC}_{\mathrm{C}}$ values. The thermodynamic study confirmed the endothermic nature of the spontaneous encapsulation process and increased degrees of randomness at the solid-liquid interface. The in vitro release results were best modelled by the zero-order and sigmoidal models. The results obtained are essential for the development of innovative vitamin E-carrier systems for application in human and veterinary medicine.
\end{abstract}

Keywords:

vitamin E, zeolite, drug encapsulation/release, kinetics, thermodynamics, mathematical modelling

\section{Introduction}

All tocopherols and tocotrienols are nonpolar and present mainly in the lipid phase. Vitamin E is the main dietary fat-soluble antioxidant, playing important roles in the body. It is a family of four tocopherols $(\alpha, \beta, \gamma$ and $\delta$ ) and four corresponding tocotrienols $(\alpha, \beta, \gamma$ and $\delta)$, of which $\alpha$-tocopherol has the highest biological activity. Vitamin E acts as a chain-breaking antioxidant preventing the propagation of free radical reactions, and thus consumption of vitamin $\mathrm{E}$ has been widely considered to help reduce risk of many chronic diseases, such as cardiovascular diseases. ${ }^{1,2}$

Besides protecting them from the harsh processing conditions and adverse storage environment, the encapsulation of bioactive compounds can also achieve targeted delivery and controlled release of entrapped nutrients to the specific site. ${ }^{2}$

"Corresponding author: Tel.: +359 898399203, E-mail: z.yaneva@abv.bg
Porous materials such as zeolites, zeolitic materials, activated carbons, silica gels, and metal oxides are of tremendous importance in many areas of research and development, mainly in adsorption, catalysis, energy storage, electrochemistry, and biomedical engineering. ${ }^{3-5}$

However, the performance of these materials in the adsorption of organic macromolecules is not optimal because of disordered pore structure, low specific pore volume, and significant amount of micropores, which only allows the adsorption of relatively small molecules. Among these porous materials, natural, modified and synthetic zeolites have been extensively used in various industrial adsorption and separation processes due to their ordered internal structure and the availability of mesopores. ${ }^{3,6}$

Adsorption of vitamin $\mathrm{E}$ on solid surfaces has attracted significant attention due to its importance for the pharmaceutical industry and medicinal field. ${ }^{7-10}$ Recently, Kavalenko and Kuznetsova reported the adsorption of vitamin $\mathrm{E}$ on carbon-con- 
taining enterosorbents to obtain drugs with slow release of the active ingredient. ${ }^{11}$ They also found that the adsorbed vitamin E molecules are oriented in such a way that their $\mathrm{OH}$-groups remain free and retain their biological activity.

An adsorption study can only be significant and useful if it includes an extensive study on adsorption equilibrium, kinetics, thermodynamics, and desorption. ${ }^{12-14}$ In the design of adsorption systems, thermodynamic properties are critical design variables in estimating the performance and predicting the mechanism of an adsorption separation process, and are also one of the basic requirements for the characterization and optimization of an adsorption process. $^{15}$

Important for the use of drug delivery systems is the knowledge about their release kinetics. Drug release depends on a number of physical and chemical properties of both the carriers and drugs, e.g., chemical composition, porosity, surface roughness, degradation ability, molecular weight, particle size, and drug-matrix interactions. ${ }^{16,17}$

The aim of the present study was to develop a new vitamin E-zeolite drug carrier system, and investigate the mass transfer mechanism of the antioxidant encapsulation and release on/from the mineral matrix by means of thermodynamic and kinetics sorption/desorption experiments and mathematical modelling of the experimental data.

\section{Materials and methods}

\section{Reagents}

Vitamin E (D, L- $\alpha$-tocopherol acetate, $\mathrm{C}_{31} \mathrm{H}_{52} \mathrm{O}_{3}$ ) (CAS No. 7695-91-2) (analytical, > 99 \% HPLC, water soluble) was supplied by Sigma-Aldrich. The natural zeolite was supplied by Bentonite AD, Kurdzhali City, Bulgaria. Its physicochemical characteristics are presented in Table $1 .{ }^{18}$ Prior to the

Table 1 -Physicochemical characteristics of natural zeolite

\begin{tabular}{ll}
\hline \multicolumn{1}{c}{ Parameter } & \multicolumn{1}{c}{ Value } \\
\hline Total pores volume, $V_{\mathrm{p}}$ & $0.11 \mathrm{~cm}^{3} \mathrm{~g}^{-1}$ \\
Micropore volume, $V_{\mathrm{m}}$ & $0.004 \mathrm{~cm}^{3} \mathrm{~g}^{-1}$ \\
Average mesopore diameter, $d_{\text {macro }}$ & $7.7 \mathrm{~nm}$ \\
Average micropore diameter, $d_{\text {micro }}$ & $0.8 \mathrm{~nm}$ \\
BET surface area & $37.1 \mathrm{~m}^{2} \mathrm{~g}^{-1}$ \\
Clinoptilolite content & $87 \%$ \\
Theoretical total ion exchange & $2.05 \mathrm{meq} \mathrm{g}^{-1}$ \\
capacity & 6.01 \\
Si/Al ratio & \\
\hline
\end{tabular}

sorption experiments, the mineral composite was thoroughly washed several times with distilled water to remove dust and any adhering substances. The natural zeolite was oven dried at $373 \mathrm{~K}$ for $48 \mathrm{~h}$. The prepared samples were stored in airtight containers for further studies. They were fractionated by sieving. The used fraction was $0.5-1.0 \mathrm{~mm}$.

\section{Surface chemistry characterization of zeolite}

Surface chemistry of zeolite was characterized by Boehm titration, $\mathrm{pH}$ of zero charge and FTIR analyses. Acidic and basic sites on the sorbent were determined by the acid-base titration (potentiometric titration) method proposed by Boehm. ${ }^{19}$ The zero surface charge $\left(\mathrm{pH}_{\mathrm{PZC}}\right)$ characteristics of natural zeolite were determined using the solid addition method. The procedure has been described elsewhere. $^{19}$

\section{FTIR spectroscopy}

The functional groups present in the fresh and vitamin-loaded zeolite were characterized by FTIR. FTIR spectra of the fresh and vitamin E-loaded zeolites were obtained with $\mathrm{KBr}$ disc technique in the range $400-4000 \mathrm{~cm}^{-1}$ using TENSOR 37 Bruker FTIR spectrometer (Bruker Optik GmbH, Germany).

\section{UV/Vis spectrophotometry}

Vitamin E concentrations were determined by an adapted UV-VIS spectrophotometric method using DR 5000 UV-Vis Spectrophotometer (Hach Lange, Germany), supplied with $10 \mathrm{~mm}$ quartz cells. All spectra were recorded in the UV region at $\lambda=285 \mathrm{~nm}$ with $2 \mathrm{~nm}$ slit width, $900 \mathrm{~nm} \mathrm{~min}^{-1}$ scan speed, and very high smoothing.

\section{Kinetics sorption studies}

The kinetic experiments were conducted in a standardized batch adsorber $(V=800 \mathrm{~mL})$ with a two-bladed impeller at initial vitamin E concentrations $\left(C_{\mathrm{o}}\right) 50$ and $250 \mathrm{mg} \mathrm{dm}^{-3}$, masses of adsorbent (w) 6 and $10 \mathrm{~g}$, at agitation rate $n=200 \mathrm{rpm}$, temperature $T=19 \pm 2{ }^{\circ} \mathrm{C}$, and $\mathrm{pH}=7$. The antioxidant solutions were separated from the adsorbent by centrifugation with Heraeus Labofuge 200 (Thermo, Electron Corporation) at 5,300 $\mathrm{g}$ for $20 \mathrm{~min}$, and filtered using $0.45 \mu \mathrm{m}$ membrane filters (LCW 916, Hach Lange, Germany) to ensure the solutions were free from adsorbent particles before measuring the residual liquid phase vitamin $\mathrm{E}$ concentrations, which were determined spectrophotometrically.

\section{In vitro release studies}

The in vitro release experiments were conducted by agitating $0.5 \mathrm{~g}$ dried vitamin E-loaded zeolite 
sample with $50 \mathrm{~cm}^{3}$ simulated gastric fluid solution, containing $0.1 \mathrm{~mol} \mathrm{dm}^{-3} \mathrm{HCl}$ and $0.1 \mathrm{~mol} \mathrm{dm}^{-3} \mathrm{NaCl}$ at $\mathrm{pH}=1.2$ and temperature $37 \pm 0.5{ }^{\circ} \mathrm{C}$. The sorbate/sorbent system was agitated on IKA_KS 130 Basic Shaker at $180 \mathrm{rpm}$ for $180 \mathrm{~min}$. Volume correction when processing the experimental data was done. Vitamin E concentrations were determined spectrophotometrically at definite time intervals until equilibrium.

\section{Thermodynamic studies}

The thermodynamic studies were accomplished by agitating three series of vitamin E solutions with volume $50 \mathrm{~mL}$ and initial concentrations $\left(C_{0}\right) 50$, $100,250,300$, and $500 \mathrm{mg} \mathrm{dm}^{-3}$ at $\mathrm{pH}=7$ with $1 \mathrm{~g}$ zeolite at $T=25,40$, and $70{ }^{\circ} \mathrm{C}$, respectively, on IKA KS 130 Basic Shaker at $180 \mathrm{rpm}$ for $120 \mathrm{~min}$. The corresponding values of the antioxidant solid phase concentrations $(q)$ were calculated by the mass balance equation Eq. (1):

$$
\left(C_{\mathrm{o}}-C_{e}\right) \cdot V=\left(q_{e}-q_{\mathrm{o}}\right) \cdot w
$$

where $C_{\mathrm{o}}\left(\mathrm{mg} \mathrm{dm}^{-3}\right)$ is the initial vitamin $\mathrm{E}$ concentration in the liquid phase, $q_{\mathrm{o}}=0\left(\mathrm{mg} \mathrm{g}^{-1}\right)-$ the sorbate concentration in the solid phase, $V\left(\mathrm{dm}^{3}\right)$ the solution volume, and $w(\mathrm{~g})$ - the sorbent mass.

\section{Interpretive modeling}

The kinetics of solute sorption is required for selecting optimum operating conditions for the fullscale batch process. Kinetics parameters are supportive for the prediction of adsorption rate and equilibrium time giving important information for designing and modelling of the sorption processes, while by the extent of applicability of the mass transfer/diffusion models and the values of the corresponding parameters, the prevailing mechanism $/ \mathrm{s}$ during vitamin $\mathrm{E}$ sorption on the mineral matrix could be determined.

Therefore, four kinetics models and two diffusion/mass transfer models were employed for testing the experimental sorption data. The kinetics sorption behavior of vitamin $\mathrm{E}$ on zeolite in the present research was modelled by the pseudo-first order, pseudo-second order, third order, mixed order kinetic models, and by the diffusion-chemisorption models by means of linear/non-linear analyses (Table 2).

The in vitro release experimental data were modelled by the zero order, first order, simplified Higuchi, Hixson-Crowell, Korsmeyer-Peppas, Weibull and sigmoidal models, which are presented in Table 2.
The values of the Gibbs free energy $\left(\Delta G^{\circ}\right)$, enthalpy $\left(\Delta H^{\circ}\right)$, and entropy $\left(\Delta S^{\circ}\right)$ give significant information in order to elucidate the adsorption thermodynamic behavior of the studied system. In this work, the values of $\Delta G^{\circ}, \Delta H^{\circ}$, and $\Delta S^{\circ}$ were estimated using the following equations:

$$
\begin{gathered}
\ln \left(\frac{q_{e}}{C_{e}}\right)=-\frac{\Delta H}{R \cdot T}+\frac{\Delta S}{R} \\
\Delta G=\Delta H-T \cdot \Delta S
\end{gathered}
$$

where $R$ is the universal gas constant $\left(8.314 \mathrm{~J} \mathrm{~mol}^{-1} \mathrm{~K}^{-1}\right)$ and $T$ is the temperature $(\mathrm{K})$.

\section{Error analysis}

Non-linear regression analysis was employed to describe the sorption behavior of the studied system by means of various mathematical equations. In order to confirm the best-fitting model(s), the data set using the values of the determined correlation coefficients $\left(R^{2}\right)$, sum of squares of errors (SSE), root-mean-square errors (RMSE), and the corrected Akaike criterion $\left(\mathrm{AIC}_{\mathrm{C}}\right)$ has to be analyzed. The linear/non-linear regression analyses were done by the data analyses and graphics software Origin 9.1 (OriginLab Corporation).

The AIC developed by Akaike is a methodology for model selection in a situation where more than one model has been fitted to experimental data and screening of the candidate models is crucial to the objectives of the research work. Akaike's general approach not only allows the best model to be identifed, but also allows the ranking of the rest of the models under consideration. ${ }^{20,21}$

In the case of least squares fit with normally distributed errors, the AIC is calculated by the following equation:

$$
A I C=N \cdot \ln \left(\frac{S S R}{N}\right)+2 \cdot k
$$

where SSR is the sum of squared residuals, $N-$ the number of experimental points, and $k$ - the number of model parameters.

The corrected Akaike criterion $\left(\mathrm{AIC}_{\mathrm{C}}\right)$ is calculated according to:

$$
A I C_{C}=A I C+\frac{2 \cdot k \cdot(k+1)}{N-k-2}
$$

The model with the minimal $\mathrm{AIC}_{\mathrm{C}}$ value of all candidate ones indicates the best model. 
Table 2 - Linear and non-linear form of the kinetics, diffusion, and desorption models applied to the vitamin E/zeolite system

\begin{tabular}{c|c|c}
\hline Linear form & Non-linear form & Basic model assumptions \\
\hline
\end{tabular}

Kinetics/diffusion sorption models

Pseudo-first order

kinetics model

$\log \left(q_{e}-q_{t}\right)=\log q_{e}-\frac{k_{1}}{2.303}$

(2) $\frac{\mathrm{d} q_{t}}{\mathrm{~d} t}=k_{1} \cdot\left(q_{e}-q_{t}\right)$
Physical adsorption - non-specific; weak van der Waals/H-forces.

Adsorption of one molecule of adsorbate by one adsorption site.
Pseudo-second order kinetics model

$$
\frac{1}{q_{t}}=\frac{1}{k_{2} \cdot q_{e}^{2}}+\frac{1}{q_{e}} \cdot t
$$

The sorption mechanism is governed by secondorder chemisorption process. $\begin{aligned} & \text { Third order } \\ & \text { kinetics model }\end{aligned} \frac{1}{q_{t}^{2}}=\frac{1}{q_{e}^{2}}+k_{3} \cdot t$
Complex kinetics order including physical and chemical sorption mechanisms.
Diffusionchemisorption model

$$
q_{t}=\frac{1}{\frac{1}{q_{e}}+\frac{1}{K_{D C} \cdot t^{0.5}}}
$$

Multi-mechanistic kinetic reaction including diffusion and chemisorption.
Intraparticle diffusion model

$q_{t}=k_{i} \cdot t^{0.5}+I$
Adsorption on porous adsorbents.

First stage - diffusion of adsorbate to the external surface of the adsorbent.

Second stage - intraparticle or pore diffusion where the adsorbates move into the inner part of the adsorbent and adsorb onto the interior sites.

Final stage - slow approach to equilibrium.
Boyd model

$$
\begin{aligned}
& F=1-\left(\frac{6}{\pi^{2}}\right) \exp \left(-B_{t}\right)(10) \\
& F=\frac{q_{t}}{q_{e}} \quad B_{t}=-0.4977 \cdot \ln (1-F)
\end{aligned}
$$

To identify if boundary layer film diffusion has any role in the rate-controlling step.

If the plot $B_{t}$ vs. $t$ is nonlinear or linear but does not pass through the origin, the limiting step is film-diffusion or chemical reaction.
Mixed order kinetics model

$$
\ln \left(\frac{1-F}{1-f_{2} \cdot F}\right)=-k_{1} \cdot t
$$

$$
q_{t}=q_{e} \cdot\left(\frac{1-\exp \left(-k_{1} \cdot t\right)}{1-f_{2} \cdot \exp \left(-k_{1} \cdot t\right)}\right)
$$

A maximum on the rate profile and an inflection point on the kinetics curve

are indicative of adsorption systems with lateral interactions and possible energetic heterogeneity. where

$$
\begin{gathered}
f_{2}=\frac{k_{2} \cdot q_{e}}{k_{1}+k_{2} \cdot q_{e}} \\
F=\frac{q_{t}}{q_{e}}
\end{gathered}
$$




\begin{tabular}{|l|l|l}
\hline Linear form & Non-linear form & Basic model assumptions \\
\hline
\end{tabular}

\section{Kinetics release models}

Zero-order model $C_{t}=k_{\mathrm{o}} \cdot t(13)$

First-order model

$\log \left(C_{t}\right)=\log C_{\mathrm{o}}-\frac{k_{1} \cdot t}{2.303}$

Higuchi model $\quad C_{t}=k_{H} \cdot t^{0.5}(15)$
Applicable for drug dissolution from dosage forms that do not disaggregate and release the drug slowly. The drug release rate is constant over a period of time.

Describes the drug dissolution of modified release pharmaceutical dosage forms, transdermal systems, matrix tablets with low soluble drugs in coated forms, osmotic systems, etc.
Describes drug dissolution in pharmaceutical dosage forms, e.g. containing water-soluble drugs in porous matrices.

The initial concentration of the drug in the matrix is significantly higher than its solubility.

Drug diffusion is one-dimensional.

The size of the drug particles is smaller than the thickness of the investigated system.

The swelling and dissolution of the matrix could be neglected.

The drug diffusion coefficient is constant.

Perfect sink conditions are always attained in the release environment.

The mathematical model is valid during the entire release process until total depletion of the drug is achieved.
Hixson-Crowell $\quad C_{\mathrm{o}}^{1 / 3}-C_{t}^{1 / 3}=K_{H C} \cdot t$ (16) model
The particles area is proportional to the cube root of their volume.

Describes drug release from systems which characterize with a change in the surface area and the particles diameter.
Korsmeyer-Peppas model $\frac{C_{t}}{C_{\mathrm{o}}}=a \cdot t^{n}$
For cylindrical tablets, $0.45 / 0.5 \leq n$ corresponds to a Fickian diffusion mechanism, $0.45 / 0.5<n<0.89$ to non-Fickian transport, $n=0.89$ to relaxational transport, and $n>0.89$ to super case II transport. Fick diffusion for $n=0.5$;

non-Fickian diffusion for $0.5<n<0.1$

For analyses of the release of pharmaceutical polymeric dosage forms, when the release mechanism is not well known or when more than one type of release could be involved.
Weibull model $\quad C_{t}=C_{\mathrm{o}} \cdot\left(1-e^{-k \cdot(t-T)}\right)$
Dissolution drug release.

Matrix type drug release.
Sigmoidal model $\frac{C_{t}}{C_{e}}=k_{s 1} \cdot(t-l)^{n_{s}}+k_{s 2} \cdot(t-l)^{n_{s}}$
Non-Fickian diffusion including diffusion and relaxation. 


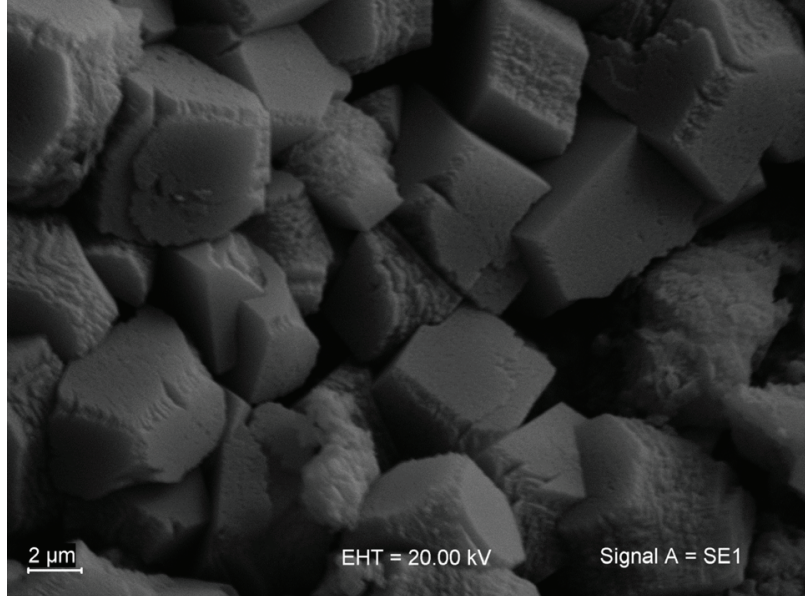

Fig. 1 - SEM image of zeolite

\section{Results and discussion}

\section{Physicochemical and morphological characterization of zeolite}

According to the experimental data from the potentiometric titration, the basic and acidic sites for zeolite were estimated at 2.5 and $6.3 \mathrm{mmol} \mathrm{g}^{-1}$, respectively, which determined the acidic surface of the mineral material. The $\mathrm{pH}_{\mathrm{pzc}}$ of zeolite is 7.34.

The SEM images of zeolite (Fig. 1) displayed the heterogeneity of the samples related to their composition.

\section{FTIR analyses of zeolite before and after vitamin E encapsulation}

According to the study of Che Man et al., ${ }^{7}$ the FTIR spectrum of vitamin E (Fig. 2a) exhibited ab-

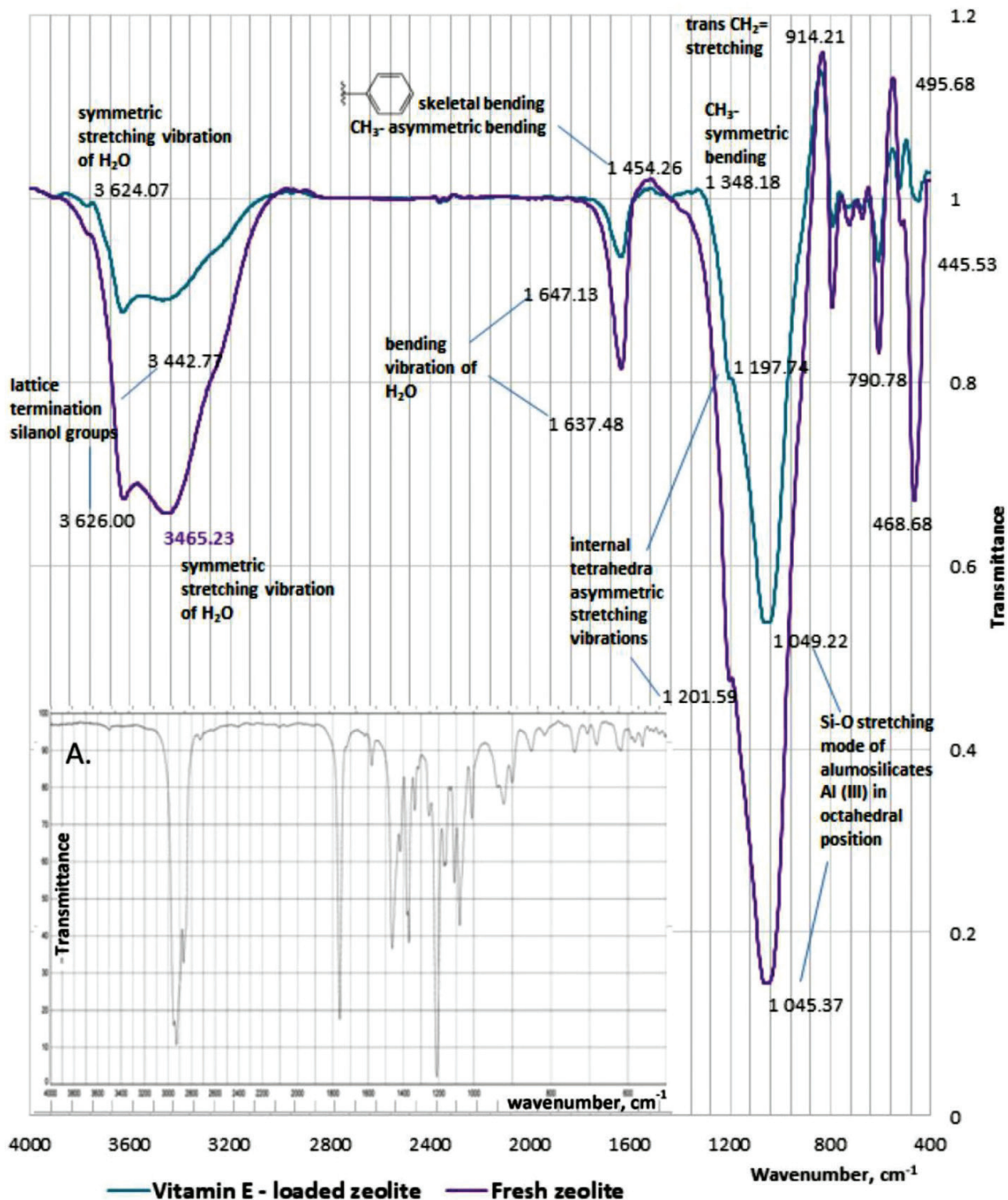

Fig. 2 - FTIR spectra of fresh zeolite, vitamin E-loaded zeolite, and pure D,L- $\alpha$-tocopherol (adapted from ${ }^{23}$ ) 
sorption bands at wavelength $3473 \mathrm{~cm}^{-1}$ for $\mathrm{OH}$-stretching vibrations; ${ }^{22}$ at $2927-2854 \mathrm{~cm}^{-1}$ for asymmetric and symmetric stretching vibrations of $\mathrm{CH}_{2}-$ and $\mathrm{CH}_{3}-$ vibrations; ${ }^{7}$ at $1460-1450 \mathrm{~cm}^{-1}$ for phenyl skeletal and methyl asymmetric bending; at $1378 \mathrm{~cm}^{-1}$ for methyl symmetric bending; at 1262 $\mathrm{cm}^{-1}$ for $-\mathrm{CH}_{2}$ vibrations; at $1086 \mathrm{~cm}^{-1}$ for plane bending vibrations of phenyl group, and at $919 \mathrm{~cm}^{-1}$ for trans $=\mathrm{CH}_{2}$ stretching. ${ }^{20}$

The characteristic FTIR spectra of fresh zeolite and vitamin E-loaded zeolite are presented in Fig. 2. The comparative analysis of the obtained FTIR spectra showed that, after the adsorption of vitamin $\mathrm{E}$ molecules in zeolite, the following variations in the intensity of relevant FTIR bands on the spectra of the loaded mineral were registered: shifting of the bands at $3473,1201,790$, and $468 \mathrm{~cm}^{-1}$ to lower frequencies: $3465,1197,773$, and $445 \mathrm{~cm}^{-1}$, respectively, and lower transmittances of the same bands; a decrease in the frequency at $3400 \mathrm{~cm}^{-1}(\mathrm{OH}$-stretching band of the strongly H-bonded zeolitic water), indicating that the adsorbed vitamin $\mathrm{E}$ molecules involved H-bonds with the zeolitic water molecules; a slight shift of the absorption bands at $796 \mathrm{~cm}^{-1}$ (for fresh zeolite) to $773 \mathrm{~cm}^{-1}$ (for vitamin E-loaded zeolite) with significant decrease in the intensity of the loaded mineral spectrum; a slight deformation of the loaded zeolite spectrum at $914 \mathrm{~cm}^{-1}$, attributed to trans- $\mathrm{CH}_{2}$-stretching vibrations of vitamin $\mathrm{E}$ molecules.

In conclusion, the strong bands assigned to vibrations of the zeolite structure were dominant; however, the characteristic vitamin E FTIR vibrational bands in the antioxidant-loaded zeolite spectra provided evidence for the presence of the vita$\min$ in the zeolite matrix.

\section{Sorption kinetics}

The experimental kinetics curves of vitamin E sorption on zeolite at $w=6$ and $10 \mathrm{~g}$ sorbent are presented in Fig. 3 as $q_{t}$ vs. $t$. Obviously, both kinetics curves were S-shaped, characterizing with the highest sorption rate in the time interval 50-100 min. The maximum established sorption capacity of the mineral towards the vitamin was $q_{t}=4.79 \mathrm{mg} \mathrm{g}^{-1}$ for the series with $6 \mathrm{~g}$ adsorbent, and $q_{t}=3.07$ $\mathrm{mg} \mathrm{g}^{-1}$ - with $10 \mathrm{~g}$ zeolite. The experimental $q_{t}$ values are calculated according to the mass balance - eq. (1):

$$
q_{t}=\frac{\left(C_{o}-C_{t}\right) \cdot V}{w}
$$

Obviously, at equal initial vitamin concentration, the sorbent capacity is inversely proportional to the zeolite quantity, i.e. the equilibrium adsorption capacity increases with a decrease in zeolite dose, as a unit mass of the mineral comes into contact with a greater number of organic molecules.

The experimental data was described by four kinetics/mass transfer mathematical models: the pseudo-first order, the mixed order kinetics models, the diffusion-chemisorption, and the intraparticle diffusion models. The characteristic model parameters were calculated by non-linear regression analyses (Table 3).

The integrative comparative analyses of the values of the predicted model parameters, coefficients, and error functions (Table 3 ) established that the intraparticle diffusion model represented satisfactorily the experimental results of the vitamin sorption on zeolite, as the values of $R_{i l}{ }^{2}$, SSE, MSE,

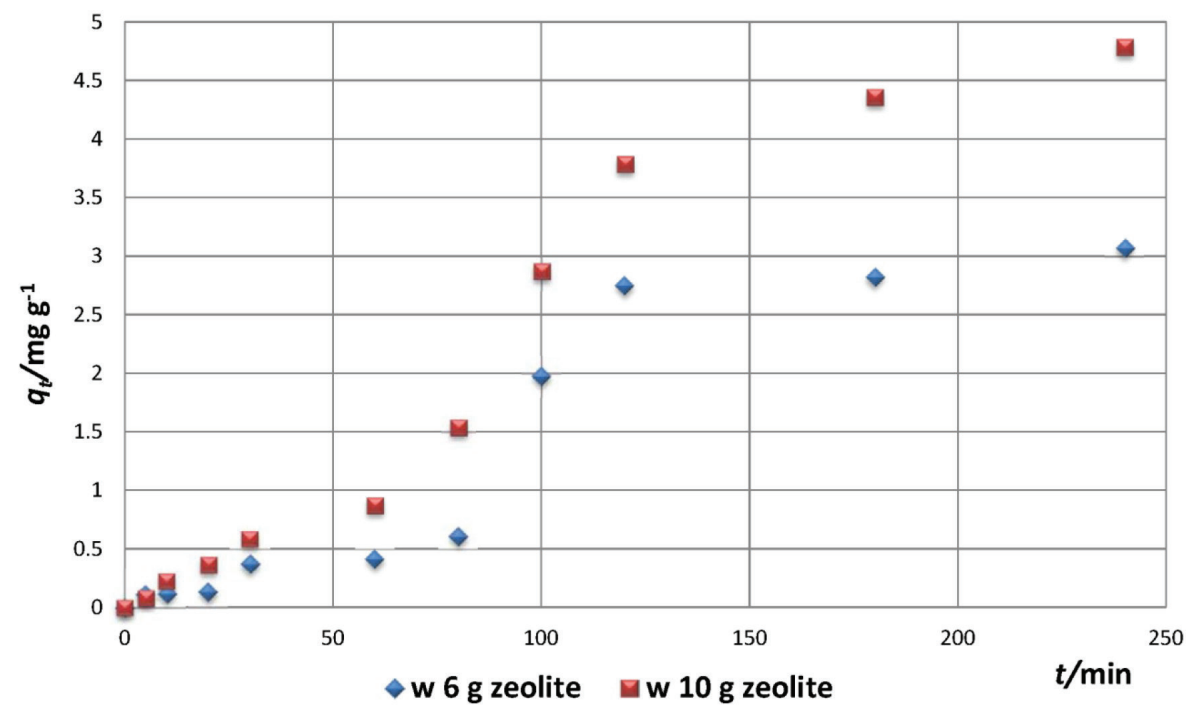

Fig. 3 - Experimental kinetics curves of vitamin E sorption on zeolite 
RMSE, and $\mathrm{AIC}_{\mathrm{C}}$ for both experimental series were acceptable.

According to Weber-Morris model, it is possible that the diffusion process can be related to different diffusion rate parameters occurring within different pore sizes or perhaps pore blockage occurring with time, which will lead to a reduction in the adsorption rate or diffusion. Thus, at least four separate regions on the plot $q_{t}$ vs. $t^{0.5}$, depicting the mass transfer onto the adsorbent: an initial portion, due to possible external mass transfer effects relating to the adsorption from solution onto the adsorbent, followed by three linear sections representing the possible intraparticle diffusion, are potentially possible to exist. ${ }^{24-26}$

The plots of $q_{t}$ versus $t^{0.5}$ for both experimental series (Fig. 4) pass through the origin and comprise of three linear sections indicative of film-diffusion (or chemical reaction), followed by macro-/mesoand micropore-diffusion. The comparative analyses of the values of the model rate parameters (Table 3) established that, for both experimental series, the values of $k_{i 2}$ are the highest, followed by these for $k_{i 3}$. Consequently, the rate-limiting mechanism of the encapsulation process is pore diffusion; however, the role of film-diffusion could not be neglected. Besides, the higher values of $k_{i 2}$ as compared to $k_{i 3}$ are indicative of the fact that probably a greater relative part of vitamin $\mathrm{E}$ molecules was incorporated in the macro- and mesopores/channels of the zeolite matrix. The latter could be explained both by the smaller number of micropores (Table 1), and the spatial organic molecule/pore size limitations.

The comparative analyses of the kinetics experimental and model data established that intraparticle diffusion was not the only rate-limiting mechanism during the antioxidant encapsulation, as the mixed-order kinetics model characterized with the highest $R^{2}$ and the lowest SSE, MSE, RMSE values. Besides, the model curves presented in Fig. 5 correlated very well with the experimental points, especially for the middle and high concentration ranges. The best applicability of the mixed-order model was also confirmed by the lowest values of $\mathrm{AIC}_{\mathrm{C}}$ for both experimental series (Table 3 ).

The values of the parameter $f$ in the mixed-order kinetics model, for the investigated systems with different zeolite mass, are negative. These parameter values correspond to a maximum on the rate profile, and an inflection point on the kinetics curve. Such mode is indicative of adsorption systems with lateral interactions and possible energetic heterogeneity. The values of the pseudo-second order and third order models are not presented in Table 3, since both kinetics models were inapplicable to the current experimental results. The latter conclusion was based both on the extremely low values
Table 3 -Values of the kinetics and diffusion parameters, correlation coefficients, and error functions for the vitamin E/zeolite system

\begin{tabular}{|c|c|c|}
\hline $\begin{array}{l}\text { Kinetics/ } \\
\text { diffusion } \\
\text { models }\end{array}$ & $\mathrm{w}=6 \mathrm{~g}$ & $\mathrm{w}=10 \mathrm{~g}$ \\
\hline $\begin{array}{l}\text { Pseudo-first } \\
\text { order kinetics } \\
\text { model }\end{array}$ & $\begin{array}{l}k_{1} 0.0247 \\
q_{\mathrm{el}} 191.69 \mathrm{mg} \mathrm{g}^{-1} \\
R_{1}^{2}=0.7971 \\
\mathrm{MSE}=1.107 \\
\mathrm{RMSE}=1.052 \\
\mathrm{AIC}_{\mathrm{C}}=8.7832\end{array}$ & $\begin{array}{l}k_{1} 0.0149 \\
q_{\mathrm{e} 1} 23.95 \mathrm{mg} \mathrm{g}^{-1} \\
R_{1}^{2}=0.8259 \\
\mathrm{MSE}=0.199 \\
\mathrm{RMSE}=0.446 \\
\mathrm{AIC}_{\mathrm{C}}=6.6704\end{array}$ \\
\hline
\end{tabular}

$\begin{array}{lll} & q_{\mathrm{eDC}} 0.6892 \mathrm{mg} \mathrm{g}^{-1} & q_{\mathrm{eDC}} 0.5304 \mathrm{mg} \mathrm{g}^{-1} \\ \text { Diffusion- } & K_{\mathrm{DC}} 0.0477 & K_{\mathrm{DC}} 0.0333 \\ \text { chemisorption } & R_{\mathrm{DC}}{ }^{2}=0.6791 & R_{\mathrm{DC}}{ }^{2}=0.6810 \\ \text { model } & \mathrm{MSE}=21.665 & \mathrm{MSE}=36.261 \\ & \mathrm{RMSE}=172.32 & \mathrm{RMSE}=290.09 \\ & \mathrm{AIC}_{\mathrm{C}}=27.1416 & \mathrm{AIC}_{\mathrm{C}}=42.1768\end{array}$

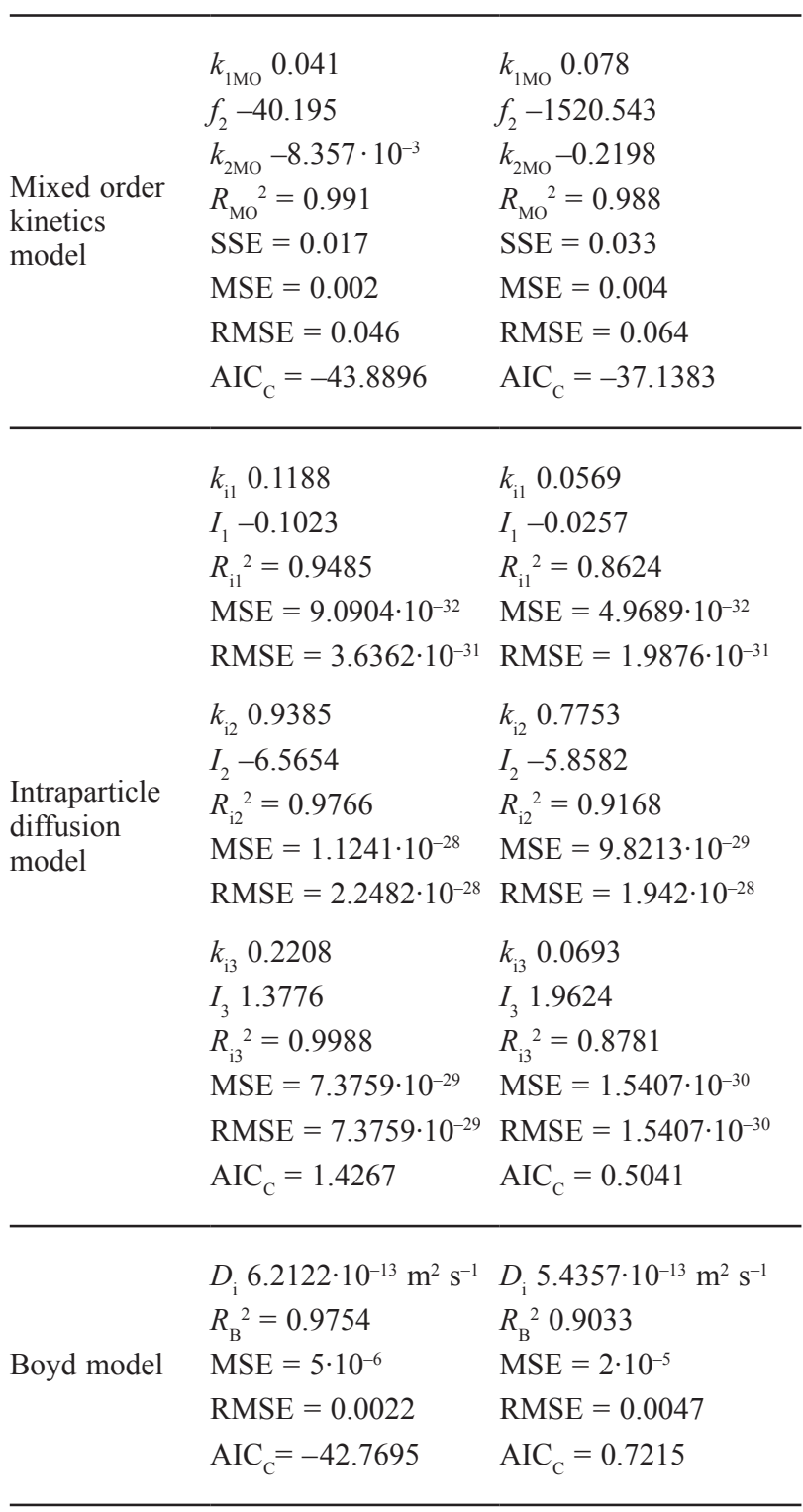




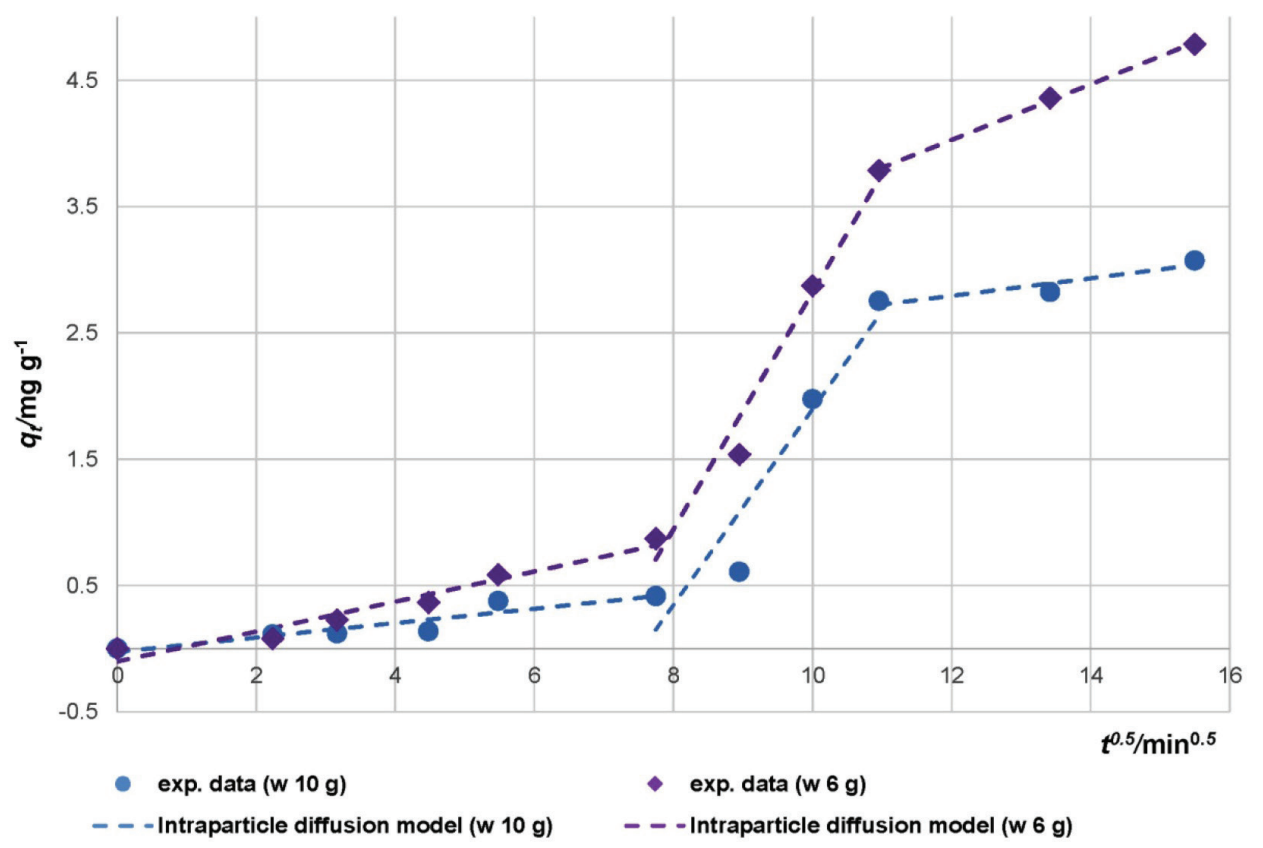

Fig. 4 - Experimental kinetics data and intraparticle diffusion model

of the obtained correlation coefficients $\left(R^{2}=0.0645\right.$ -0.1819 ), and the significant deviation of the model curves as compared to the experimental points.

According to Boyd model, if the intraparticle diffusion is the adsorption rate controlling step, then the plot of Bt vs. $t$ (Boyd plot) produces a straight line, which passes through the origin. The Boyd's coefficient, $B$, is determined by the slope of $B t v s$. $t$, and the values of the effective intraparticle diffusion coefficient, $D_{i}$, by the following equation:

$$
B=\frac{\pi^{2} \cdot D_{i}}{r^{2}}
$$

If the plot is nonlinear or linear but does not pass through the origin, it can then be concluded that the limiting step is film-diffusion or chemical reaction. ${ }^{27,28}$ According to the Boyd experimental and model results presented graphically in Fig. 6, the plot intercepts the origin and consists of three linear segments (two breakpoints) (Fig. 6). Consequently, according to Boyd's criterion, it can be concluded that intraparticle diffusion was the rate-controlling step during the antioxidant encapsulation on the mineral matrix. The calculated values of $D_{i}$ by the Boyd model for the studied systems are presented in Table 3.

\section{Mechanism of vitamin E encapsulation}

To outline the probable host-guest interactions between vitamin E molecules and the zeolite structure during the process of the antioxidant encapsulation, insight into the molecular structure and prop- erties of the drug, as well as the morphological and physicochemical characteristics of the inorganic matrix is necessary. The molecular characteristics of vitamin E (Table 4) were calculated by Chem 3D Draw software package. In addition, the approximate dimensions of the organic molecule in the 3D coordinate system were determined by Marvin ChemAxon software package (Fig. 7).

According to scientific literature, natural zeolites belong to the group of mesoporous mineral materials with the following pore/channel diameters: micropores $d<1.5-2.0 \mathrm{~nm}$; mesopores 1.5 (2.0) $>d>40(50) \mathrm{nm}$; macropores $d>40(50)$ nm. ${ }^{29}$ In view of these data, it could be concluded that the antioxidant molecules could enter and leave the meso- and macropores of the solid matrix without serious spatial limitations. Whereas, the extent of diffusion in the micropores and microchannels obviously depends on the spatial orientation of the drug molecules, which could in turn render resistance and limit the free path for encapsulation.

Table 4 -Molecular characteristics of vitamin $E$

\begin{tabular}{lc}
\hline \multicolumn{1}{c|}{ Parameter } & Value \\
\hline Formal charge & 0 \\
Connolly accessible area, $\AA^{2}$ & 904.217 \\
Connolly molecular area, $\AA^{2}$ & 501.272 \\
Connolly solvent excluded volume, $\AA^{3}$ & 478.49 \\
$M_{\mathrm{m}}, \mathrm{g} \mathrm{mol}^{-1}$ & 444.6896 \\
Ovality & 1.6944 \\
\hline
\end{tabular}



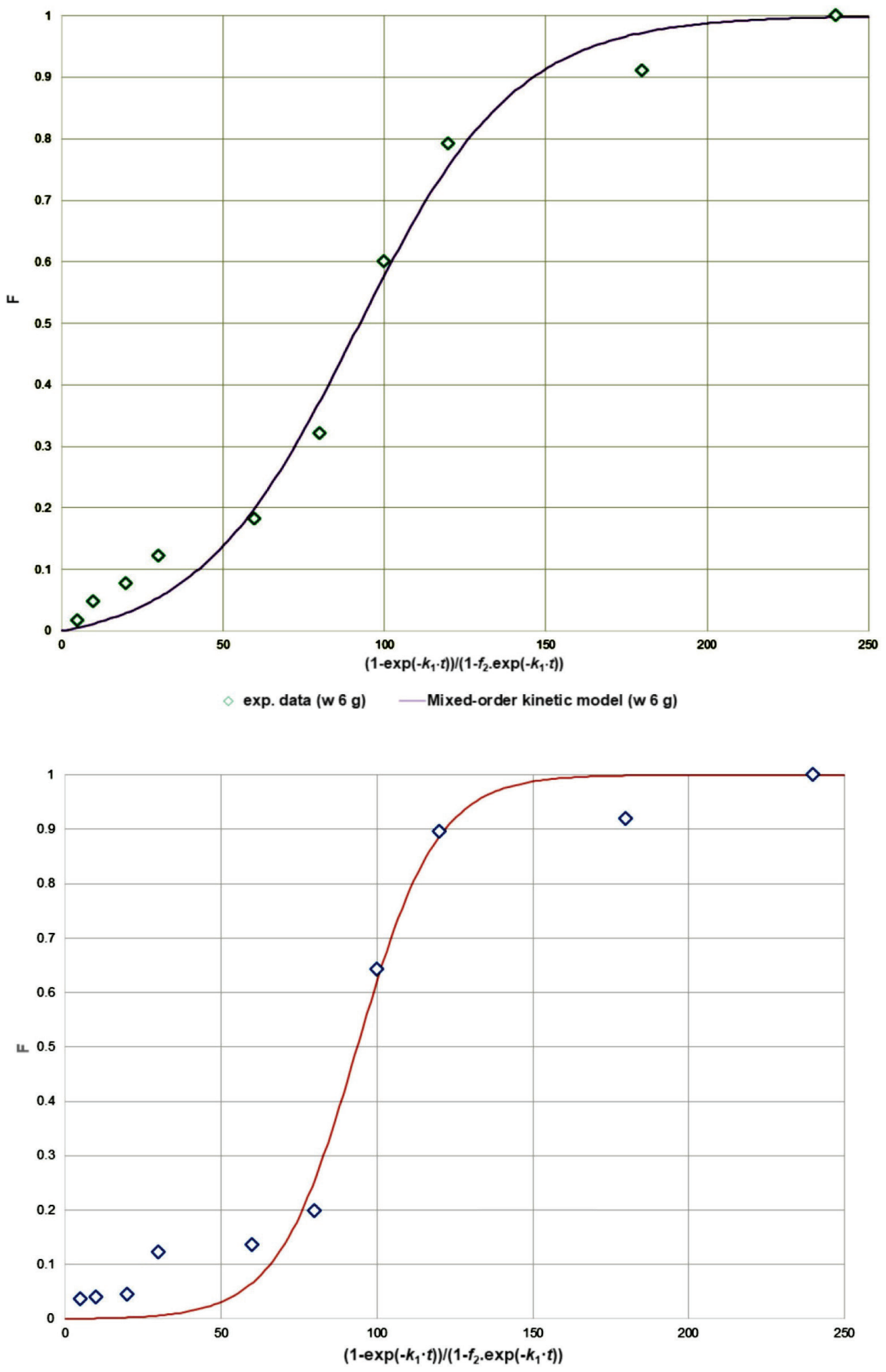

exp. data $(\mathrm{w} 10 \mathrm{~g}) \quad$ Mixed-order kinetic model (w $10 \mathrm{~g})$

Fig. 5 - Experimental kinetics data and mixed-order kinetics model 


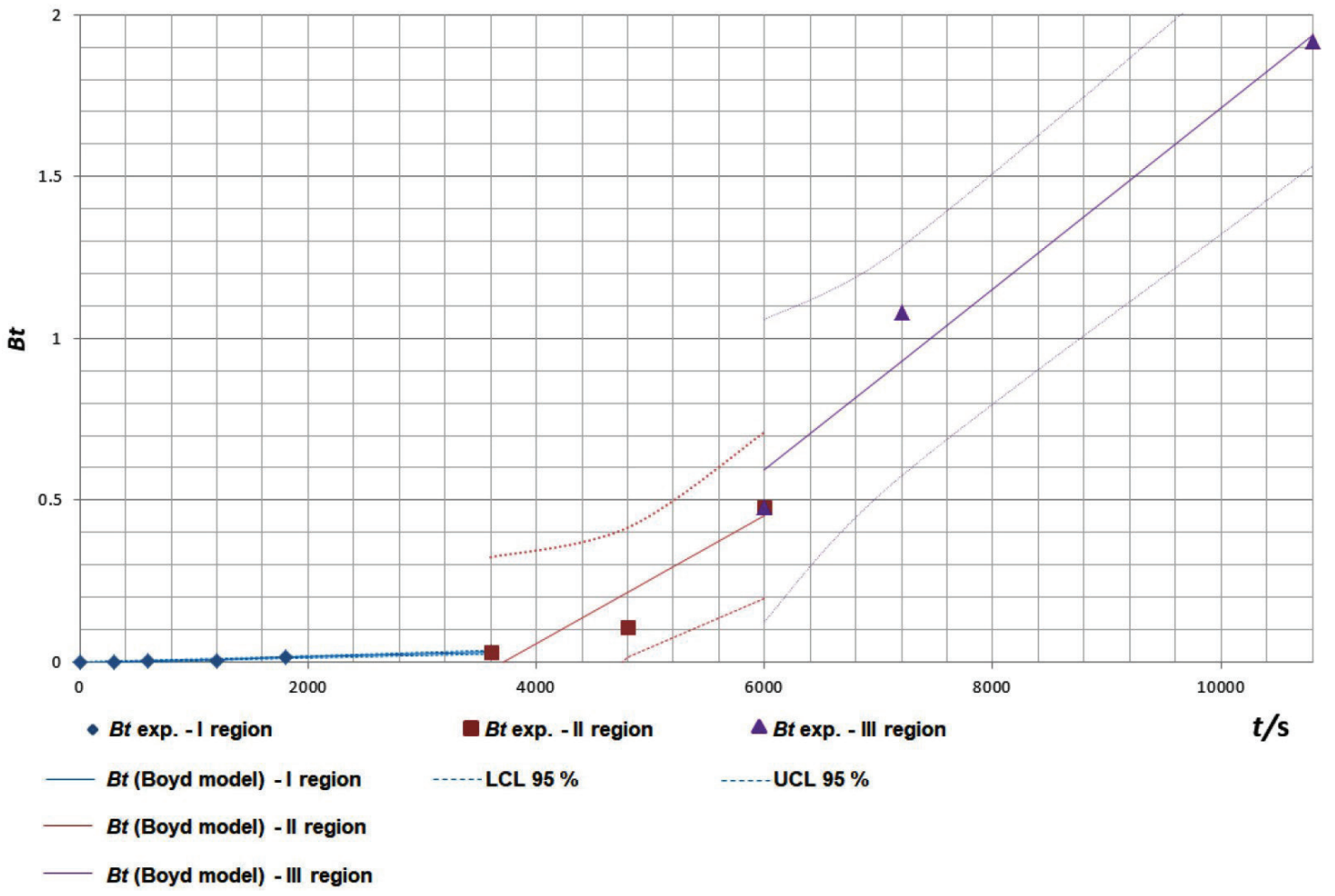

Fig. 6 - Experimental and model Boyd plot of vitamin E encapsulation with $w 6$ zeolite
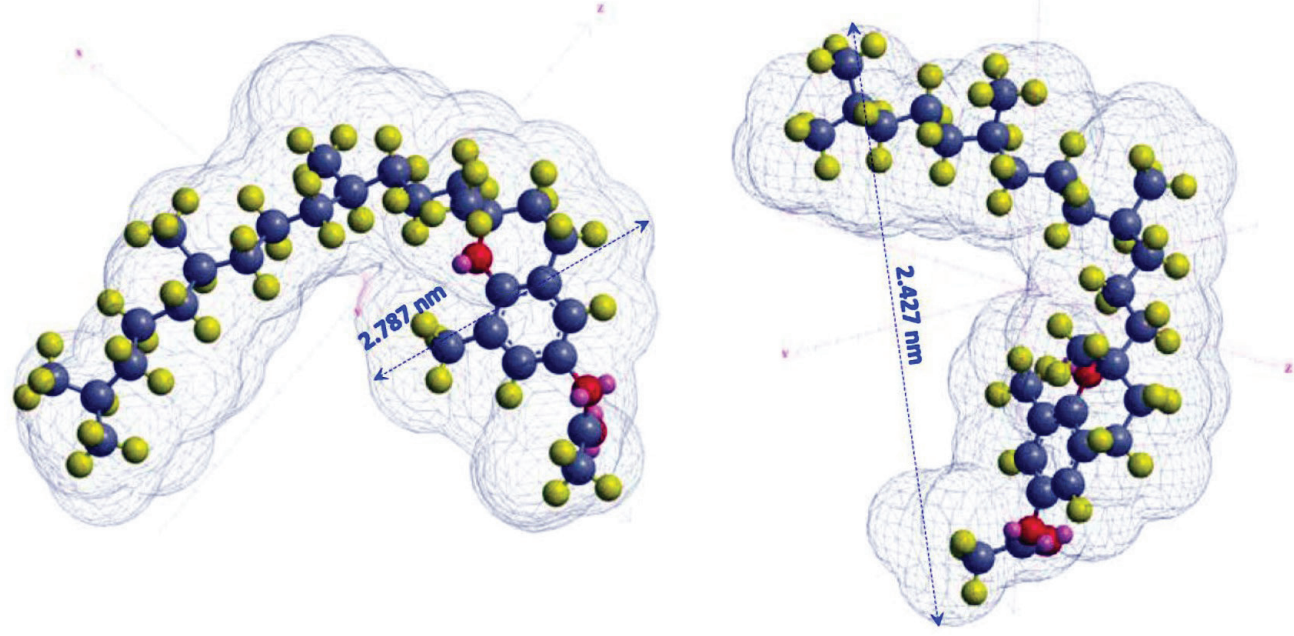

Fig. 7 - Connolly molecular area and molecular dimensions of vitamin E molecule

The localization of $\alpha$-tocopherol molecules on individual adsorption sites is possible due to hydrogen bonding between their phenol hydroxyl groups and isolated $\mathrm{Si}-\mathrm{OH}$ groups of the sorbent. ${ }^{30,31}$ The formation of a monomolecular layer of the antioxidant molecules on the sorbent surface leads to the emergence of additional energetically nonequivalent adsorption sites. The further observed increase in the sorption extent is probably caused by the formation of polymolecular $\alpha$-tocopherol layers. Association of vitamin $\mathrm{E}$ molecules via hydrophobic interactions is possible. However, according to the study of Bidzilya et al., such tendency occurs at solution concentrations above $5 \cdot 10^{-3} \mathrm{~mol} \mathrm{dm}^{-3}$ (i.e. $\left.2223 \mathrm{mg} \mathrm{dm}^{-3}\right){ }^{30,32}$ 


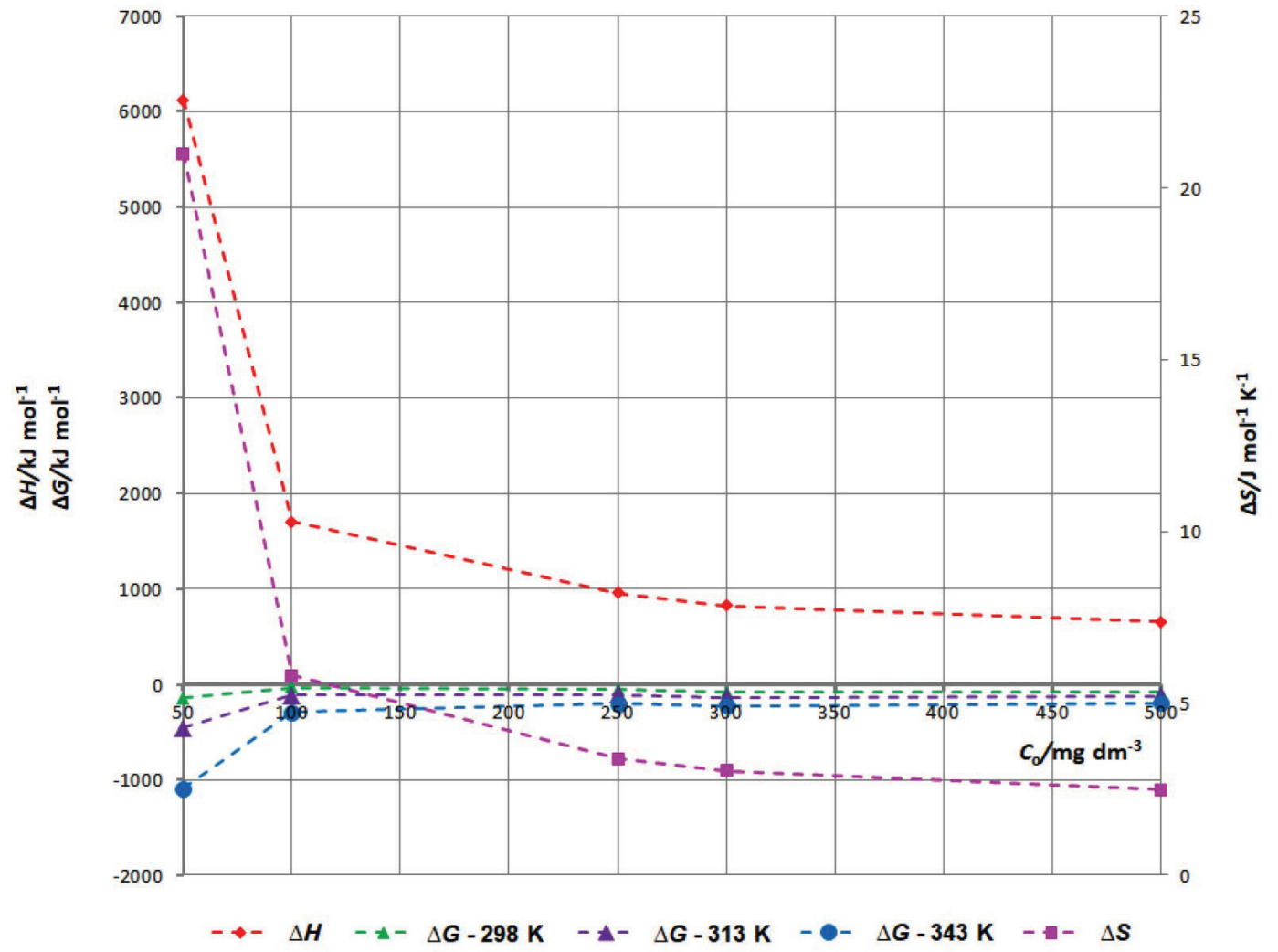

Fig. 8 -Dependence of the values of the thermodynamic parameters on vitamin $E$ initial concentration

\section{Thermodynamic study}

The values of the calculated thermodynamic parameters for the system vitamin E/zeolite are presented in Table 4, and their dependence on the initial vitamin $\mathrm{E}$ concentration in Fig. 8. The positive values of $\Delta H^{\circ}$ suggested the endothermic nature of the adsorption process of the vitamin on the mineral material. The values of the free energy change $\left(\Delta G^{\circ}\right)$ were negative, and decreased with temperature increase (Table 5, Fig. 8), indicating that the adsorption of vitamin $\mathrm{E}$ on zeolite was spontaneous and the adsorption became more favorable at a higher temperature. The fact that they were lower than $-80 \mathrm{~kJ} \mathrm{~mol}^{-1}$ indicated the chemical nature of

Table 5 -Values of the thermodynamic parameters of vitamin E adsorption on zeolite

\begin{tabular}{r|c|c|c|c|c}
\hline \multirow{2}{*}{$\begin{array}{c}C_{\mathrm{o}^{\prime}} \\
\mathrm{mg} \mathrm{L}^{-1}\end{array}$} & $\begin{array}{c}\Delta H^{\mathrm{o}}, \\
\mathrm{kJ} \mathrm{mol}^{-1}\end{array}$ & $\begin{array}{c}\Delta S^{\mathrm{o}}, \\
\mathrm{kJ} \mathrm{mol}^{-1} \mathrm{~K}^{-1}\end{array}$ & \multicolumn{3}{|c}{$\Delta G^{\mathrm{o}}, \mathrm{kJ} \mathrm{mol}^{-1}$} \\
\cline { 5 - 7 } & 6118.69 & 21.00 & -140.50 & -455.56 & -1085.68 \\
100 & 1701.04 & 5.81 & -30.55 & -117.71 & -292.03 \\
250 & 958.60 & 3.39 & -52.99 & -103.91 & -205.75 \\
300 & 823.28 & 3.05 & -86.81 & -132.62 & -224.24 \\
500 & 652.70 & 2.48 & -85.14 & -122.29 & -196.57 \\
\hline
\end{tabular}

the host-guest interactions. The positive values of $\Delta S^{\circ}$ displayed that the degrees of randomness increased at the solid-liquid interface during the adsorption of the biologically active substance on the mineral.

\section{Release studies}

The use of in vitro drug dissolution data to predict in vivo bioviability of biologically active substances can be considered as the rational development of controlled release formulations. ${ }^{33,34}$ Model-dependent methods are based on different mathematical functions, which describe the dissolution profile. Once a suitable function had been selected, the dissolution profiles were evaluated depending on the derived model parameters.

According to the experimental data, the highest extent of vitamin $\mathrm{E}$ release from the zeolite matrix in simulated gastric fluid solution was $3.0 \mathrm{mg} \mathrm{dm}^{-3}$, which is equal to desorption efficiency $E_{d e s} 6 \%$ at $298 \mathrm{~K}$ achieved after $180 \mathrm{~min}$. The experimentally determined vitamin concentration in the zeolite matrix was $4.35 \mathrm{mg} \mathrm{g}^{-1}$. Based on the data for the dietary reference intakes of vitamin $\mathrm{E}$, the released antioxidant quantity is equivalent to $6.66 \mathrm{IU}$ (1 IU of the synthetic form is equivalent to $0.45 \mathrm{mg}$ of $\alpha$-tocopherol), which is within the Recommended Dietary Allowances (RDAs) for humans. ${ }^{35}$ The lat- 


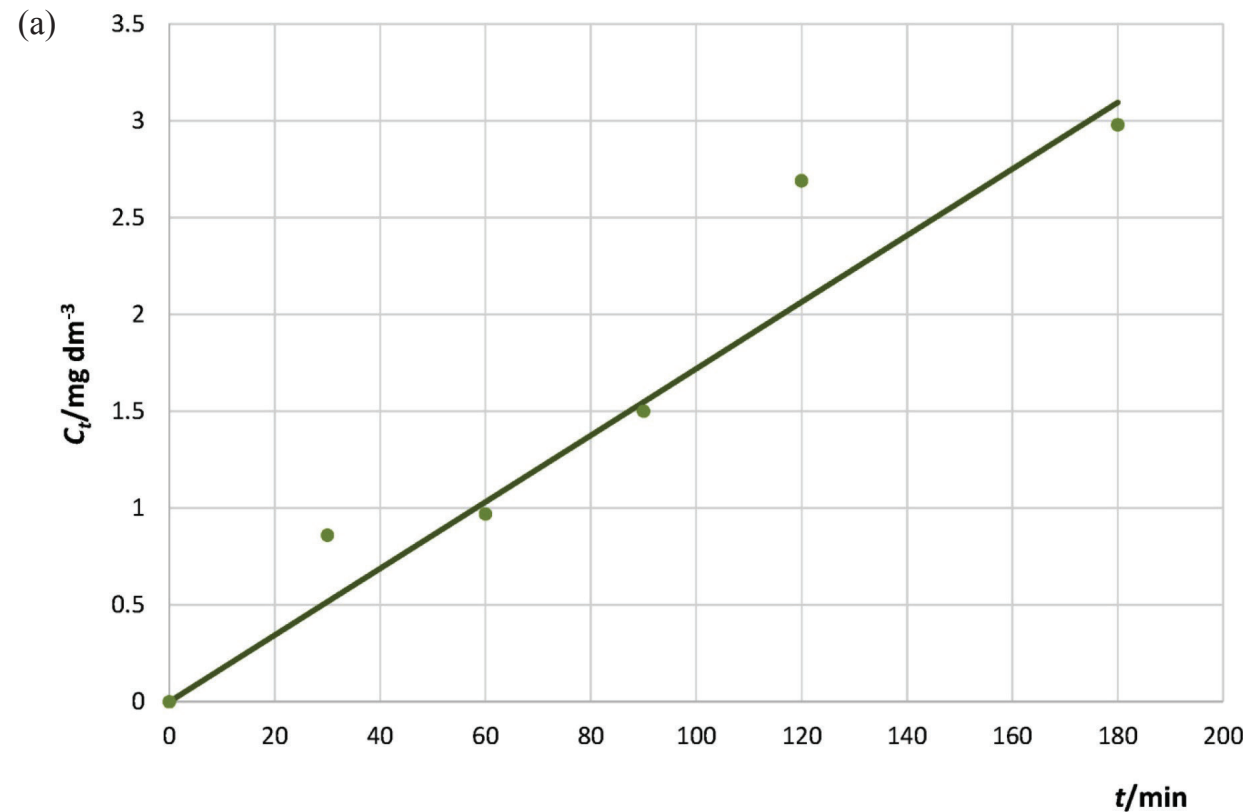

- exp. data zero-order model

(b)

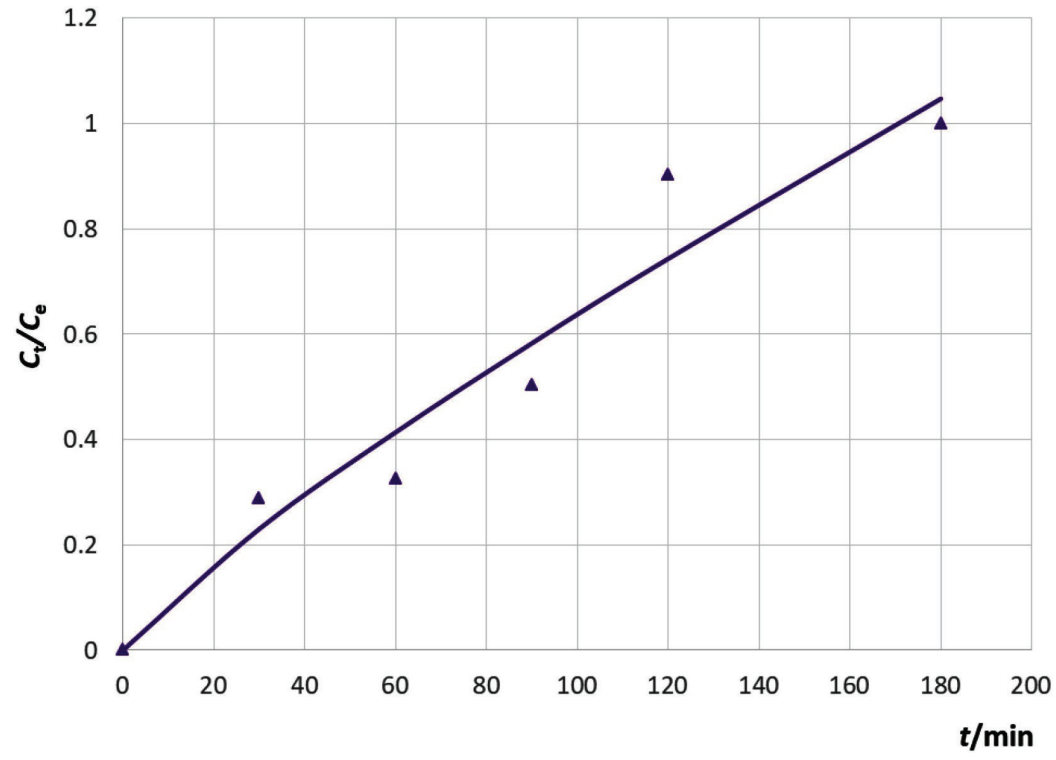

$\Delta$ exp. data Korsmeyer-Peppas model

Fig. 9 - Applicability of: a) the zero-order model, and b) Korsmeyer-Peppas model to the experimental data for vitamin $E$ release from zeolite

ter experimental result proved undoubtedly the efficiency of vitamin E-loaded zeolite for medical applications. In order to determine the suitable release kinetic model describing the dissolution profile of vitamin E, nonlinear regression was applied. The experimental results from the in vitro desorption studies in simulated gastric fluid $(\mathrm{pH}=1.2)$ were modelled by the zero-order, first-order, Higuchi, Hixson-Crowell and Korsmeyer-Peppas, Weibull, and sigmoidal models. The values of the model parameters are presented in Table 6 .
The zero-order model (Fig. 9a) displayed significant correlation towards the experimental data $\left(R^{2}=0.9332 ; \mathrm{AIC}_{\mathrm{C}}=-12.235\right)$. Concerning drug release, the dosage forms following this profile, release the same amount of drug by unit time, and it is the ideal method of drug release in order to achieve a prolonged pharmacological action. In addition, it is the ultimate goal of all controlled-release drug-delivery mechanisms. It leads, in principle, to the best control of plasma concentration and offers several advantages, including improved pa- 
Table 6 -Values of the desorption parameters for the vitamin E/zeolite system

\begin{tabular}{|c|c|}
\hline Desorption model & Parameters \\
\hline Zero-order model & $\begin{array}{l}k_{\mathrm{o}}=0.0171 \\
R^{2}=0.9332 \\
\mathrm{AIC}_{\mathrm{C}}=-12.235\end{array}$ \\
\hline First-order model & $\begin{array}{l}C_{\mathrm{o}}=0.6485 \\
k_{1}=-0.0092 \\
R^{2}=0.8917 \\
\mathrm{AIC}_{\mathrm{C}}=3.8186\end{array}$ \\
\hline Higuchi model & $\begin{array}{l}k_{\mathrm{H}}=0.2287 \\
R^{2}=0.8730 \\
\mathrm{AIC}_{\mathrm{C}}=-1.5226\end{array}$ \\
\hline Hixson-Crowell model & $\begin{array}{l}k_{\mathrm{HC}}=-1 \cdot 10^{-4} \\
R^{2}=0.7719 \\
\mathrm{AIC}_{\mathrm{C}}=23.6272\end{array}$ \\
\hline Korsmeyer-Peppas model & $\begin{array}{l}a=1.2988 \cdot 10^{-2} \\
n=0.8453 \\
R^{2}=0.8960 \\
\mathrm{AIC}_{\mathrm{C}}=-7.0929\end{array}$ \\
\hline Weibull model & $\begin{array}{l}C_{\mathrm{o}}=8.943 \\
k=0.002 \\
T=-4.152 \\
R^{2}=0.8990 \\
\mathrm{AIC}_{\mathrm{C}}=-6.7706\end{array}$ \\
\hline Sigmoidal model & $\begin{array}{l}k_{s 1}=1.866 \cdot 10^{-3} \\
k_{s 2}=-4.45 \cdot 10^{-9} \\
n_{\mathrm{s}}=1.5 \\
R^{2}=0.950 \\
\mathrm{AIC}_{\mathrm{C}}=-15.7963\end{array}$ \\
\hline
\end{tabular}

tient compliance and reduced frequency of drug administration. ${ }^{12-14}$

Drug dissolution from dosage forms that do not disaggregate and release the drug slowly can also be represented by the zero-order model. This relationship can be used to describe the drug dissolution of several types of modified release pharmaceutical dosage forms, as in the case of some transdermal systems, as well as matrix tablets with low soluble drugs in coated forms, osmotic systems, etc. ${ }^{36}$ However, the applicability of the Weibull (Fig. 10 ) and Korsmeyer-Peppas (Fig. 9b) models could not be fully neglected due to the acceptable values of the regression coefficients $\left(R^{2} \sim 0.89\right)$ and $\mathrm{AIC}_{\mathrm{C}}$ (Table 6).

The release exponent $n$ of Korsmeyer-Peppas kinetic model describes the drug release mechanism: Fick diffusion for $n=0.5$; non-Fickian diffusion for $0.5<n<0.1$. The value of $n=0.8453$ ob- tained in the present study (Table 6), indicates a change in vitamin $\mathrm{E}$ release mechanism from pseudo-Fickian diffusion to anomalous or non-Fickian antioxidant release. ${ }^{37}$ Non-Fickian behavior needs two or more parameters to describe the interacting diffusion and relaxation effect inherent in it. ${ }^{38}$ The latter conclusions imposed the necessity of applying a proper mathematical model, which could describe such complex release behavior. The sigmoidal drug release model, presented graphically in Fig. 11, characterized with the best correlation with the experimental data of the release of vitamin $\mathrm{E}$ from zeolite. The latter was confirmed by the highest value of the regression coefficient and the lowest $\mathrm{AIC}_{\mathrm{C}}$ value (Table 6). The significantly higher value of the kinetics constant $k_{\mathrm{s} 1}$ as compared to $k_{s 2}$ (Table 6) is indicative of the considerable role of diffusion. The inflexion point registered at approximately $50 \%$ equilibrium release outlines an initial stage where the rate of desorption exceeds that of sorption and a second region characteristic of decreased desorption rate.

In this respect, the study of Tabandeh and Mortazavi ${ }^{39}$ proved minor contribution of Higuchi model due to diffusion of $\alpha$-tocopherol from the outermost bilayers of the multilamellar large vesicles (MLVs) to a liposomal gel. The second phase of the antioxidant release profile showed a non-Fickian release indicating a more prominent role for diffusion. This combinational release profile provided a high initial concentration of $\alpha$-tocopherol followed by a slow release throughout a 10 -hour period.

In the case of mesoporous materials, one of the possibilities to incorporate non-constant diffusivity is the assumption that the diffusion coefficient of drugs depends on the matrix porosity ${ }^{40}$ In the present study, considering the fact that the relative part of the micropores volume is only $3.6 \%$ (Table 1) from the total pores volume, the spatial and dimensional limitations of these pores towards the vitamin macromolecules, it could be concluded that the diffusivity of the organic molecules during their release would not be much dependent on the zeolite microporosity.

Recent scientific studies on the design, applicability, and efficiency of innovative vitamin E carrier and drug-zeolite composite systems (Table 7), outlined the competitiveness and reliability of the newly developed antioxidant-zeolite formulation in the present study. Significant comparability between the values of the cited encapsulation and release efficiencies (eq. 26) and these obtained in the current investigations is observed.

$$
E, \%=\frac{C_{\mathrm{o}}-C_{t}}{C_{\mathrm{o}}} \cdot 100
$$


(a)

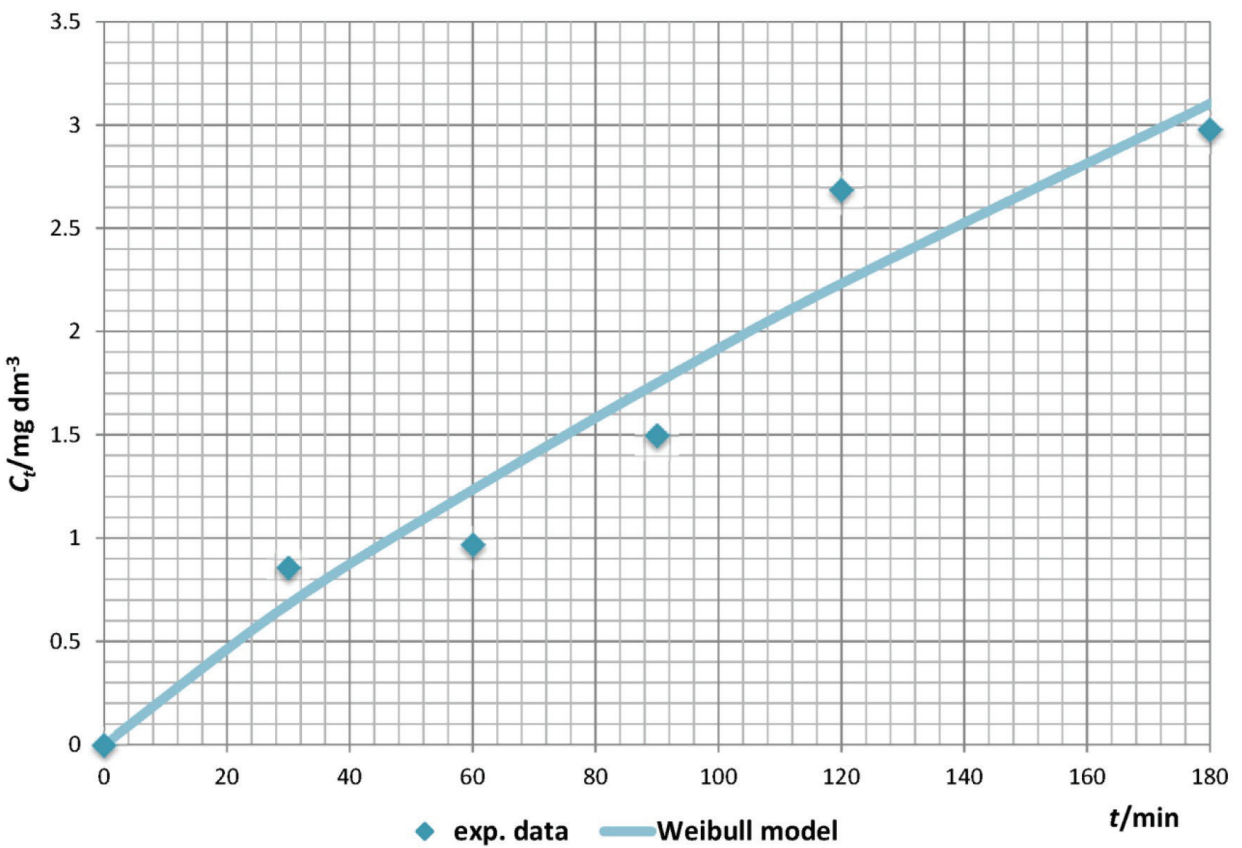

Fig. 10 -Applicability of Weibull model to the experimental data for vitamin E release from zeolite

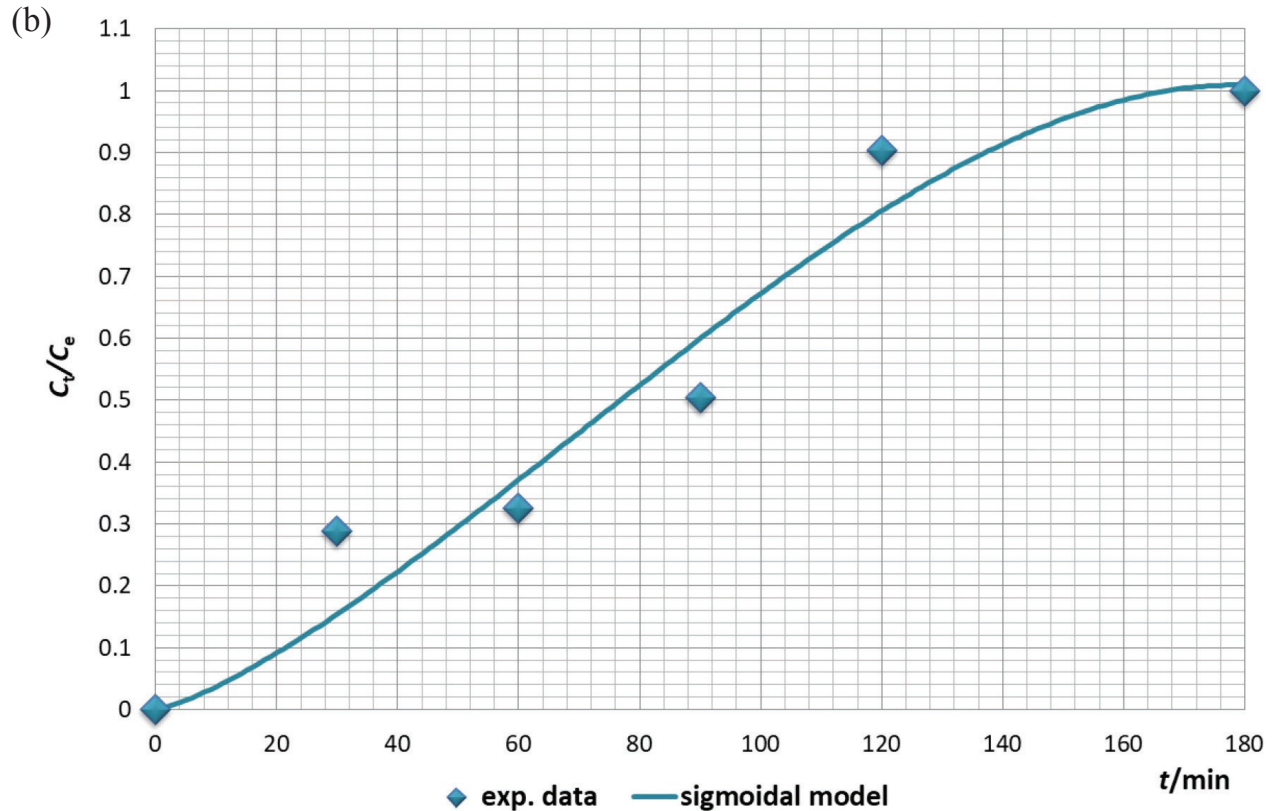

Fig. 11 - Applicability of the sigmoidal model to the experimental data for vitamin E release from zeolite

\section{Conclusion}

The current study has provided insights into the encapsulation/release behavior of the vitamin E/ zeolite system. The physicochemical nature of the antioxidant sorption on the mineral matrix was confirmed by SEM, FTIR, and UV/VIS spectrophotometric analyses. The sorption kinetics followed the mixed order kinetics model, thus the intraparticle diffusion was not the sole rate-limiting step. The thermodynamic study proved the endothermic, spontaneous, and feasible nature of the antioxidant encapsulation process. The attained vitamin E release efficiency in simulated gastric fluid for 180 min was within the Recommended Dietary Allowances (RDAs) for humans. A complex mechanism of vitamin E release from the zeolite matrix, in which diffusion plays a significant role, was observed. The results from the present study are essential as they could be applied during the development of innovative vitamin E carrier systems for human and veterinary medicine. 
Table 7 -Literature review on vitamin E carrier and drug-zeolite composite systems

\begin{tabular}{|c|c|c|c|}
\hline Drug/carrier system & Encapsul. efficiency & Release efficiency & Ref. \\
\hline vitamin E/zein-chitosan complex & $76.6-87.8 \%$ & $90 \%$ & 2 \\
\hline tocopherol/inulin microspheres & $86-90 \%$ & $15 \%$ & 41 \\
\hline vitamin E/acid-modified clinoptilolite tuff & $29 \%$ & - & 32 \\
\hline tocopherol/liposomal gel & $98.6 \%$ & $1 \%$ & 39 \\
\hline tocopherol/protein-based nanoformulations & $99 \%$ & - & 42 \\
\hline$\alpha$-tocopherol/thermosensitive polymer nanoparticles & $40.5-50.5 \%$ & $70-100 \%$ & 43 \\
\hline indomethacin +zeolite $13 \mathrm{X}$ & $24.54 \%$ & $<10 \%$ & 44 \\
\hline ibuprofen +zeolite $13 \mathrm{X}$ & $25.28 \%$ & $<10 \%$ & 44 \\
\hline indomethacin +zeolite $\mathrm{Y}$ & $25.75 \%$ & $<10 \%$ & 44 \\
\hline ibuprofen +zeolite Y & $26.32 \%$ & $<10 \%$ & 44 \\
\hline resveratrol/Zeolite $\mathrm{Y}$ & $37.1 \%$ & $27 \%(5 \mathrm{~h})$ & 45 \\
\hline vitamin E/zeolite & $68.1-72.9 \%$ & $6 \%(180 \mathrm{~min})$ & this study \\
\hline
\end{tabular}

\section{ACKNOWLEDGEMENT}

The study was supported financially by Scientific Project No. 04/16 VMF, Faculty of Veterinary Medicine, Trakia University, Stara Zagora, Bulgaria.

\section{Nomenclature}

$$
\begin{aligned}
& \mathrm{AIC}_{\mathrm{C}} \quad \text { - corrected Akaike criterion } \\
& B \quad-\text { Boyd model coefficient } \\
& C_{\mathrm{e}} \quad-\text { equilibrium liquid phase concentration, } \mathrm{mg} \mathrm{dm}^{-3} \\
& C_{\text {o }} \quad-\text { initial solution concentration, } \mathrm{mg} \mathrm{dm}^{-3} \\
& \text { d - pore/channel diameter, } \mathrm{nm} \\
& D_{i} \quad \text { - intraparticle diffusion coefficient } \\
& k \quad-\text { Weibull model parameter } \\
& k_{1} \quad-\text { first-order rate constant } \\
& k_{2} \quad-\text { second-order rate constant } \\
& k_{3} \quad-\text { third-order rate constant } \\
& k_{s 1} \quad-\text { rate constant in the sigmoidal release model } \\
& k_{s 2} \quad-\text { rate constant in the sigmoidal release model } \\
& K_{\mathrm{DC}} \quad-\text { rate constant in the diffusion-chemisorption } \\
& k_{\mathrm{H}} \quad-\text { Higuchi model rate constant } \\
& K_{\mathrm{HC}} \quad-\text { Hixson-Crowell model rate constant } \\
& k_{i} \quad-\text { rate constant in the intraparticle diffusion } \\
& \text { model } \\
& k_{\mathrm{o}} \quad-\text { zero-order rate constant } \\
& M_{\mathrm{m}} \quad-\text { molecular weight, } \mathrm{g} \mathrm{mol}^{-1} \\
& n \quad-\text { Korsmeyer-Peppas model exponent } \\
& n_{\mathrm{s}} \quad-\text { sigmoidal model exponent } \\
& \mathrm{pH}_{\mathrm{PZC}} \quad \text { - point of zero charge } \\
& q_{e} \quad-\text { equilibrium encapsulation/sorption capacity }
\end{aligned}
$$

$q_{t} \quad-$ encapsulation/sorption capacity of the solid phase at time $t, \mathrm{mg} \mathrm{g}^{-1}$

$R \quad-$ universal gas constant, $R=8.314 \mathrm{~J} \mathrm{~mol}^{-1} \mathrm{~K}^{-1}$

$r \quad-$ particle radius, $\mathrm{mm}$

$R^{2} \quad-$ correlation coefficient

RMSE - root-mean-square error

SEM - scanning electron microscope

SSE - sum of squares of errors

$T \quad-$ temperature, ${ }^{0} \mathrm{C}, \mathrm{K}$

$t \quad-$ time, $\min$

$V \quad-$ solution volume, $\mathrm{cm}^{3}$

w $\quad-$ zeolite mass, $\mathrm{g}$

$\Delta G^{\mathrm{o}} \quad-$ Gibbs free energy, $\mathrm{kJ} \mathrm{mol}^{-1}$

$\Delta H^{\circ} \quad-$ enthalpy, $\mathrm{kJ} \mathrm{mol}^{-1}$

$\Delta S^{\mathrm{o}} \quad-$ entropy, $\mathrm{kJ} \mathrm{mol}^{-1} \mathrm{~K}^{-1}$

$\alpha \quad-$ Korsmeyer-Peppas model parameter

$\lambda \quad-$ wavelength, $\mathrm{nm}$

\section{References}

1. Tucker, J., Townsend, D., Alpha-tocopherol: Roles in prevention and therapy of human disease, Biomed. Pharmacother. 59 (2005) 380 doi: https://doi.org/10.1016/j.biopha.2005.06.005

2. Luo, Y., Zhang, B., Whent, M., Yu, L., Wang, Q., Preparation and characterization of zein/chitosan complex for encapsulation of $\alpha$-tocopherol, and its in vitro controlled release study, Colloids and Surfaces B 85 (2011) 145. doi: https://doi.org/10.1016/j.colsurfb.2011.02.020

3. Hartmann, M., Vinu, A., Chandrasekar, G., Adsorption of vitamin $\mathrm{E}$ on mesoporous carbon molecular sieves, Chem. Mater. 17(4) (2005) 829.

4. Tomashevich-Canovich, M., Purification of natural zeolite-clinoptilolite for medical application. Extraction of lead, J. Serb. Chem. Soc. 70(11) (2005) 1335. doi: https://doi.org/10.2298/JSC0511335T 
5. Marczewski, A., Marczewska, A., Slota, A., Adsorption and desorption kinetics of benzene derivatives on mesoporous carbons, Adsorption 19 (2013) 391. doi: https://doi.org/10.1007/s10450-012-9462-7

6. Georgieva, N., Yaneva, Z., Comparative evaluation of natural and acid-modified layered mineral materials as rimifon-carriers using UV/VIS, FTIR and equilibrium sorption study, Cogent Chemistry 1(1069723) (2015) 1. doi: https://doi.org/10.1080/23312009.2015.1069723

7. Che Man, Y., Ammawath, W., Mirghani, M., Determining $\alpha$-tocopherol in refined bleached and deodorized palm olein by Fourier transform infrared spectroscopy, Food Chem. 90 (2005) 323 doi: https://doi.org/10.1016/j.foodchem.2004.05.059

8. Yoo, S., Song, Y., Chang, P., Lee, G., Microencapsulation of $\alpha$-tocopherol using sodium alginate and its controlled release properties, Int. J. Biol. Macromol. 38(1) (2006) 25. doi: https://doi.org/10.1016/j.ijbiomac.2005.12.013

9. Faizal, C., Hoshina, Y., Kobayashi, T., Scaffold membranes for selective adsorption of $\alpha$-tocopherol by phase inversion covalently imprinting technique, J. Membr. Sci. 322 (2008) 503. doi: https://doi.org/10.1016/j.memsci.2008.05.046

10. Hategekimana, J., Masamba, K., Ma, J., Encapsulation of vitamin E: Effect of physicochemical properties of wall material on retention and stability, Carbohydr. Polym. 124 (2015) 172 . doi: https://doi.org/10.1016/j.carbpol.2015.01.060

11. Kovalenko, G., Kuznetsova, E., Adsorption of antiseptics (furacilin, chlorhexidine) and vitamin E on carbon-containing enterosorbents. Drug synthesis methods and manufacturing technology, Pharm. Chem. J. 34(6) (2000) 327 doi: https://doi.org/10.1007/BF02524417

12. Senthil Kumar, P., Ramalingam, S., Senthamarai, C., Niranjana, M., Vijayalakshmi, P., Sivanesan, S., Adsorption of dye from aqueous solution by cashew nut shell: Studies on equilibrium isotherm, kinetics and thermodynamics of interactions, Desalination 261(1-2) (2010) 52. doi: https://doi.org/10.1016/j.desal.2010.05.032

13. Dotto, G., Vieira, M., Esquerdo, V., Pinto, L., Equilibrium and thermodynamics of azo dyes biosorption onto Spirulina platensis, Braz. J. Chem. Eng. 30(01) (2013) 13 doi: https://doi.org/10.1590/S0104-66322013000100003

14. Sivarajasekar, M., Baskar, R., Adsorption of Basic Magenta II onto $\mathrm{H}_{2} \mathrm{SO}_{4}$ activated immature Gossypium hirsutum seeds: Kinetics, isotherms, mass transfer, thermodynamics and process design, Arab. J. Chem. 2014(1) (2014) in press. doi: https://doi.org/10.1016/j.arabjc.2014.10.040

15. Hong, S., Wen, Ch., He, J., Gan, F., Ho, Y., Adsorption thermodynamics of Methylene Blue onto bentonite, J. Haz. Mat. 167(1-3) (2009) 630. doi: https://doi.org/10.1016/j.jhazmat.2009.01.014

16. Wise, D., Handbook of pharmaceutical controlled release technology. NY: Marcel Dekker, CRS Press, 2000, pp 155 183.

17. Costa, P., Lobo, M., Modelling and comparison of dissolution profiles, Eur. J. Pharm. Sci. 13 (2001) 123 doi: https://doi.org/10.1016/S0928-0987(01)00095-1

18. Allen, S., Ivanova, E., Koumanova, B., Adsorption of sulfur dioxide on chemically modified natural clinoptilolite. Acid modification, Chem. Eng. 152(2-3) (2009) 389 doi: https://doi.org/10.1016/j.cej.2009.04.063

19. Yaneva, Z., Staleva, M., Georgieva, N., Study on the hostguest interactions during caffeine encapsulation into zeolite, Eur. J. Chem. 6(2) (2015) 169. doi: https://doi.org/10.5155/eurjchem.6.2.169-173.1228
20. Mutua, F. M., The use of the Akaike information criterion in the identification of an optimum flood frequency model, Hydrolog. Sci. J. 39(3) (1994) 235. doi: https://doi.org/10.1080/02626669409492740

21. Yaneva, Z. L., Koumanova, B. K., Georgieva, N. V., Linear and nonlinear regression methods for equilibrium modelling of $\rho$-nitrophenol biosorption by Rhizopus oryzae: Comparison of error analysis criteria. J. Chem. 2013 (2013) 1.

22. Guillen, M., Cabo, N., Infrared spectroscopy in the study of edible oils and fats, J. Sci. Food. Agric. 75(1) (1997) 1 doi: https://doi.org/10.1002/(SICI)1097-0010(199709)75:1 $<1::$ AID-JSFA842>3.0.CO; 2-R

23. FTIR spectrum, D, L- $\alpha$-Tocopherol acetate T3376, Documents, Merck.

24. Weber, W. J., Morris, J. C., Kinetics of adsorption on carbon from solution, J. San. Eng. Div. Am. Soc. Civil Eng. 89(2) (1963) 31.

25. Allen, S. J., McKay, G., Khader, K. Y. H., Intraparticle diffusion of basic dye during adsorption onto Sphagnum peat, Environ. Pollut. 56(1) (1989) 39. doi: https://doi.org/10.1016/0269-7491(89)90120-6

26. Allen, S. J., Koumanova, B., Kircheva, Z., Nenkova, S., Adsorption of 2-nitrophenol by technical hydrolysis lignin: Kinetics, mass transfer, and equilibrium studies. Ind. Eng. Chem. Res. 44 (2005) 2281 doi: https://doi.org/10.1021/ie049455d

27. Dada, A., Folahan, A., Odebunmi, E., Kinetics, mechanism, isotherm and thermodynamic studies of liquid-phase adsorption of $\mathrm{Pb}^{2+}$ onto wood activated carbon supported zerovalent iron (WAC-ZVI) nanocomposite, Cogent Chemistry 3 (2017) 1351653. doi: https://doi.org/10.1080/23312009.2017.1351653

28. Viegas, R. M. C., Campinas, M., Costa, H., Rosa, M. J., How do the HSDM and Boyd's model compare for estimating intraparticle diffusion coefficients in adsorption processes, Adsorption 20 (2014) 737. doi: https://doi.org/10.1007/s10450-014-9617-9

29. Kowalczyk, P., Sprynskyy, M., Terzyk, A. P., Lebedynets, M., Namiesnik, J., Buszewski, B., Porous structure of natural and modified clinoptilolites, J. Colloid. Interf. Sci. 297 (2006) 77. doi: https://doi.org/10.1016/j.jcis.2005.10.045

30. Bidzilya, V. A., Golovkova, L. P., Vlasova, N. N., Davidenko, N. K., Makovetskaya, V. V., Bogomaz, V. I., Adsorption of $\alpha$-tocopherol and its analogues with highly disperse silica, Ukrainski Khimicheski Zhurnal 60(9) (1994) 616.

31. Slavinskaya, O., Laguta, I., Kuzema, P., Adsorption properties of highly disperse silica with partially hydrophobic surface, Zhurnal Fizicheskoi Khimii 80(8) (2006) 1482.

32. Kotova, D., Yu, S., Vasilyeva, T., Isotherm of $\alpha$-tocopherol adsorption on acid activated clinoptilolite tuff, Colloid $\mathrm{J}$ 75(1) (2013) 84. doi: https://doi.org/10.1134/S1061933X13010067

33. Dash, S., Murthy, P. N., Nath, L., Chowdhur, P., Kinetic modeling on drug release from controlled drug delivery systems, Acta Pol. Pharm. - Drug Res. 67(3) (2010) 217.

34. Yan, Sh., Zhang, H., Piao, J., Chen, Y., Gao, Sh., Lu, Ch., Niu, L., Xia, Y., Hu, Y., Ji, R., Wang, H., Xu, X., Studies on the preparation, characterization and intracellular kinetics of JD27-loaded human serum albumin nanoparticles, Procedia Eng. 102 (2015) 590. doi: https://doi.org/10.1016/j.proeng.2015.01.133

35. Institute of Medicine. Food and Nutrition Board. Dietary Reference Intakes: Vitamin C, Vitamin E, Selenium, and Carotenoids external link disclaimer. Washington, DC: National Academy Press 2000. 
36. Raj, C., Kumar, P., Kumar, K., Kinetics and drug release studies of isoniazid encapsulated with PLA-COPEG/gold nanoparticles, Int. J. Pharm. Pharm. Sci. 4(4) (2012) 398

37. Dinu, M. V., Cocarta, A. I., Dragan, E. S., Synthesis, characterization and drug release properties of $3 \mathrm{D}$ chitosan/ clinoptilolite biocomposite cryogels, Carbohydr. Polym. 153 (2016) 203

doi: https://doi.org/10.1016/j.carbpol.2016.07.111

38. Crank, J., The mathematics of diffusion, $2^{\text {nd }}$ Edition, Oxford University Press (1975) 254-266.

39. Tabandeh, H., Mortazavi, S., An investigation into some effective factors on encapsulation efficiency of alpha-tocopherol in MLVs and the release profile from the corresponding liposomal gel, Iran J. Pharm. Res. 12 (Suppl.) (2013) 21.

40. Murzin, D. Y., Heikkila, T., Modelling of drug dissolution kinetics with sigmoidal behavior from ordered mesoporous silica, Chem. Eng. Commun. 201(5) (2014) 579. doi: https://doi.org/10.1080/00986445.2013.782290

41. Garcia, P., Vega, J., Jimenez, P., Santos, J., Robert, P., Alpha-tocopherol microspheres with cross-linked and acetyl- ated inulin and their release profile in a hydrophilic model, Eur. J. Lipid Sci. Technol. 115 (2013) 811.

doi: https://doi.org/10.1002/ejlt.201200109

42. Ghaheh, F. S., Alihosseini, A. K. F., Gomes, A., Ribeiro, A. Cavaco-Paulo, A., Silva, C., Protein-based nanoformulations for $\alpha$-tocopherol encapsulation, Eng. Life Sci. 17 (2017) 523 .

doi: https://doi.org/10.1002/elsc.201600188

43. Quintero, C., Vera, R., Perez, L., $\alpha$-Tocopherol loaded thermosensitive polymer nanoparticles: Preparation, in vitro release and antioxidant properties, Polímeros 26(4) (2016) 304.

doi: https://doi.org/10.1590/0104-1428.2324

44. Khodaverdi, E., Honarmandi, R., Alibolandi, M., Evaluation of synthetic zeolites as oral delivery vehicle for anti-inflammatory drugs, Iran J. Basic Med. Sci. 17(5) (2014) 337.

45. Popova, M., Yoncheva, K., Szegedi, A., Kalvachev, Y., Benbassat, N., Mavrodinova, V., Resveratrol loading on mesoporous silica and zeolite carriers by solid state method, Bulg. Chem. Commun. 46(A) (2014) 117. 